\title{
FARMERS' PERCEPTION AND WILLINGNESS TO PAY FOR PESTICIDES CONCERNING QUALITY AND EFFICACY
}

\author{
B. M. D. P. Bandara' ${ }^{1}$, N. R. Abeynayake ${ }^{2}$, L. Bandara ${ }^{3}$ and G. H. I. Anjalee ${ }^{2}$
}

\begin{abstract}
The purpose of this study was to assess farmers 'perception and willingness to pay for pesticides concerning quality \&efficacy, and exploring the socio-demographic factors that influence the decision to pay for pesticides. A sample of 141 farmers in Hambanthota and Dambulla regions was selected and information were collected by using a structured questionnaire. An econometric model called "Binary Logistic Regression" was carried out using six explanatory variables after screening out of twelve variables in the Chi-Square analysis to identify factors highly likely to affect farmers' perception and willingness to pay. The results revealed that four variables namely; age, average monthly income, pest intensity and action have a significant relationship with farmers' perception and willingness to pay for pesticides concerning quality and efficacy. Average monthly income and action have a positive impact on perception and willingness to pay while age and pest intensity have a negative impact.
\end{abstract}

Keywords: Pesticides, Quality, Efficacy, Willingness-to-pay

\section{INTRODUCTION}

Pesticide is a chemical used to control, repel, or destroy pests of any sort. It may be a chemical substance, biological agent, antimicrobial, disinfectant or device used against any pest.

In today's modern world, it is controversial that the aspects between consumer and farmer. Consumer always expects their food to be more safe and nutritious and farmer expect to have a good harvest. Consumers have also become used to food, particularly fruit and vegetables, not having any blemishes or other marks, but don't tend to think about how farmers produce food or how it gets from the farm to the shops in "perfect" condition.

Over the many years, farmers have changed their way of producing food in order to meet the expectations of consumers, supermarkets and Governments. In doing so, they have made many changes. This often includes the use of pesticides.

Even though it is important of using pesticides to satisfy both farmers' and consumers' needs, at the same time there is a big impact on human health as well as environment, because, most of the pesticides are highly toxic and dangerous for both human and environment.

\section{Environmental effects}

Pesticide use increases a number of environmental problems. Over 98\% of sprayed insecticides and $95 \%$ of herbicides reach different destinations other than their target species, including non-target species, air, water and soil. Pesticide drift occurs when pesticides suspended in the air as particles are carried by wind to other areas, potentially

2 Department of Agribusiness Management, Faculty of Agriculture and Plantation Management, 
contaminating them. Pesticides are one of the causes of water pollution, and some pesticides are persistent organic pollutants and contribute to soil contamination. In addition, pesticide use also reduces biodiversity and results in lower soil quality, reduction of nitrogen fixation, decline of pollinators, reduction of habitats, especially for birds, and can threaten endangered species.

\section{Health effects}

Pesticides can be dangerous to consumers, farmers and close bystanders during manufacture, transport, or during and after use. Due to long term exposure to pesticides can raise exposure problems related either to pesticide usage or pesticide-related illnesses. Considering this, it is prudent to limit pesticide exposure and to use the least toxic chemical pesticide or non-chemical alternative.

Though it has a negative impact on human health and environment, but still growers/ farmers use pesticides, because, their general belief is that chemical can quickly solve pest problems rather than having non chemical solutions. Due to this perception today's pesticides have been the most important agrochemicals in both world and local scenario.

\section{Global Pesticide Market}

According to the report of, "Who Owns Nature? Corporate Power and the Final Frontier in the Commodification of Life" produced by Action Group on Erosion, Technology and Concentration (2008), world's top 10 pesticide firms are as Table 01

The top 10 companies control $89 \%$ of the global agrochemical market. The worldwide market for agrochemicals was US\$38.6 billion in 2007 - up $8.4 \%$ over the previous year. The top 6 companies accounted for $\$ 28.8$ billion, or $75 \%$ of the total market.

In 2007 the four largest pesticide companies (Bayer, Syngenta, BASF, Dow) reported double-digit sales jumps. Pesticide revenues are up in nearly all regions, but Latin America (particularly Brazil, Argentina and Mexico) and Eastern Europe were the key growth markets. Still glowing from his company's stellar performance in 2007, the CEO of BASF Plant Science estimates that by 2025 the global agrochemical market will be worth \$US50 billion.

Table 01: World's Top 10 Pesticide Firms

\begin{tabular}{lcc}
\hline \multicolumn{1}{c}{ Company } & $\begin{array}{c}\text { Agrochemical sales } 2007 \\
\text { (US\$ millions) }\end{array}$ & $\begin{array}{c}\text { Global Agrochemical Mar- } \\
\text { ket 2007 Sales }\end{array}$ \\
\hline Bayer (Germany) & $\$ 7,458$ & $19 \%$ \\
Syngenta (Switzerland) & $\$ 7,285$ & $19 \%$ \\
BASF (Germany) & $\$ 4,297$ & $11 \%$ \\
Dow AgroSciences (USA) & $\$ 3,779$ & $10 \%$ \\
Monsanto (USA) & $\$ 3,599$ & $9 \%$ \\
DuPont (USA) & $\$ 2,369$ & $6 \%$ \\
Makhteshim Agan (Israel) & $\$ 1,895$ & $5 \%$ \\
Nufarm (Australia) & $\$ 1,470$ & $4 \%$ \\
Sumitomo Chemical (Japan) & $\$ 1,209$ & $3 \%$ \\
Arysta Lifescience (Japan) & $\$ 1,035$ & $3 \%$ \\
Others & - & $11 \%$ \\
Total & $\$ 34,396$ & - \\
\hline
\end{tabular}

Source: Agro World Crop Protection News, August 2008 


\section{Perception and Willingness to pay}

Perception and willingness to pay are two different psychological factors often come under in various marketing surveys. Perception is the way of conceiving something or the way we look at something and willingness to pay is about the quality or state of being willing to pay, or free choice or consent of the will, or freedom from reluctance, or readiness of the mind to do or forbear. Every marketing study tries to touch the perception and willingness of consumers because, consumer market covers vast area and always susceptible to change accordance with economic, political, cultural factors. Studying the Perception and Willingness to pay of farmers is also somewhat difficult and a big challenge because, farmers' perception and willingness is also controlled by variety of factors.

In investigating the past literature, the studies on perception and willingness to pay have been conducted by many researchers. The study assesses farmers' perceptions and willingness to pay for a bio-pesticide developed from Metarhizium anisopliae fungi carried out by Adetonah et al., 2007 has observed a sample of conventional and organic cotton producers which was randomly selected in cotton producing zones in Benin and has interviewed for their perceptions on the efficacy of the biopesticide and the likely prices they are willing to pay for the product to control a major pest like Helicoverpa armigera or cotton bollworm causing substantial crop losses and the econometric model (Logit) has been used to identify factors highly likely to affect farmer's willingness to purchase the product. Based on the statistical results of the research, three variables influencing farmers' willing to pay for bio-pesticides from Metarhizium were efficacy, agro-ecological zone and broad spectrum.

Apart from the main title related to pesticides there are several researches have been conducted relating perception and willingness to pay and the statistical analysis carried out here. Govindasamy et al., (2001) have carried out a research on Premium for Integrated Pest Management Produce: A Logistic Approach which empirically evaluates the demographic characteristics that influence consumers to pay a premium for Integrated Pest Management (IPM) grown produce. Results indicate that females, those with higher annual incomes, younger individuals, and those who frequently purchase organic produce are all more likely to pay a premium for IPM produce.

In the Sri Lankan context, researches conducted regarding perception and willingness to pay is few in quantity as well as quality. Especially marketing researches done considering pesticide market by integrating farmers' perception and willingness to pay cannot be seen. Therefore the objectives of the study are to (1) assess farmers' perception and willingness to pay for pesticides concerning quality and efficacy and to (2) determine the socio-demographic factors that influence the decision to pay for pesticides.

\section{MATERIALS ND METHODOS}

Binary Logistic Regression was selected as the regression method in this analysis to investigate farmer's decision for buying pesticides concerning quality and efficacy because; Logistic regression is the common method for the estimation of willingness to pay (WTP) (Govindasamy et al., 2001) and also logistic regression is often chosen if the response variable is in binary form and predictor variables are a mix of continuous and categorical variables.

The empirical model measuring the probability that a farmer is willing to pay for pesticides concerning quality and efficacy is expressed as below:

$$
P_{i}=F\left(W T P_{i}\right)=F\left(X_{i} \beta+\varepsilon_{i}\right)=\frac{1}{1+e^{-W T P_{i}}}=\frac{1}{1+e^{-\left(X_{i} \beta+\varepsilon_{i}\right)}}
$$


$P_{i}$ is the probability function and $W T P_{i}$ is willingness to pay where, 1 (one) indicate that an individual would be willing to pay $10 \%$ higher amount after upgrading the pesticides for higher efficacy and quality and 0 (Zero) otherwise. The figure $10 \%$ was obtained after considering the average minimum cost of production for upgrade pesticide. $X_{i}$ is a vector of observed characteristics of demand. They include socio-demographic, attitudinal and behavioral variables, $\beta$ is a vector with the corresponding estimated variables' coefficients. The error vector $\varepsilon_{i}$ consists of unobservable random variables.

\section{Data Collection}

The study was carried out using a structured questionnaire to investigate the willingness of farmers to pay for pesticides by concerning quality and efficacy of products. Perception of willingness to pay was taken as binary variable, "Yes" and "No" according to their willingness of payment for above explained criteria. Data were collected through a face to face interview conducted with farmers in two main agricultural regions in Sri Lanka, namely Hambanthota and Dambulla for the period of December 2009 to April 2010 selecting 76 farmers randomly from Badulla and 65 farmers from Hambanthota using farmer registration lists obtained from the famer-societies in the regions. These areas have been selected according to the significant contribution of Sri Lankan agriculture. Data collection was mainly targeted in two stages. In the first stage Ambilipitiya, Weeraketiya, Walasmulla, Ambalanthota, Suriyawewa, Ranna and Angunukolapellessa were covered under the Hambanthota region and the second stage was carried out in the city of Dambulla where, the large number of farmers was coming from different areas.

\section{Data Analysis}

Firstly, a Chi-Square analysis was carried out to select variables which have a strong relationship with the response/dependant variable. Then the Binary Logistic Regression was used to identify factors highly likely to affect farmers' perception and willingness to pay for pesticides concerning quality and efficacy using the factors selected from the chi-square analysis. Both the analysis was performed using Minitab (Version 15.0) statistical software.

\section{RESULTS AND DISCUSSION}

\section{Descriptive statistics of some observed facts}

In addition to examine the perception and willingness of farmer's to pay for pesticides concerning quality and efficacy, questions were also included to ascertain several factors which influence farmers' general buying behavior.

Out of total respondents of 141, 14.2\% respondents are using Traditional Pest Control (TPC) methods to overcome pest problems while $85.8 \%$ of respondents have not indicated the use of TPC methods (Figure 01). Neem seed extraction, Kalawel and Compost are the most popular TPC methods among the respondents. Though the majority has given up the use of TPC methods, still users and non users believe that the TPC methods are long lasting and successful than the use of chemicals (pesticides). But because of time consumption, need of large quantities and application problems they have adapted to chemical solutions.

Tendency towards buying new pesticides normally depends on the performance of previous products. Out of total respondents, $62.4 \%$ showed no tendency if the pesticides being used now are performing well while $37.6 \%$ showed tendency towards buying new products. They said that the most of the pesticides do not give the expected result when it is used several times. As a result, they always try to move new pesticides. 


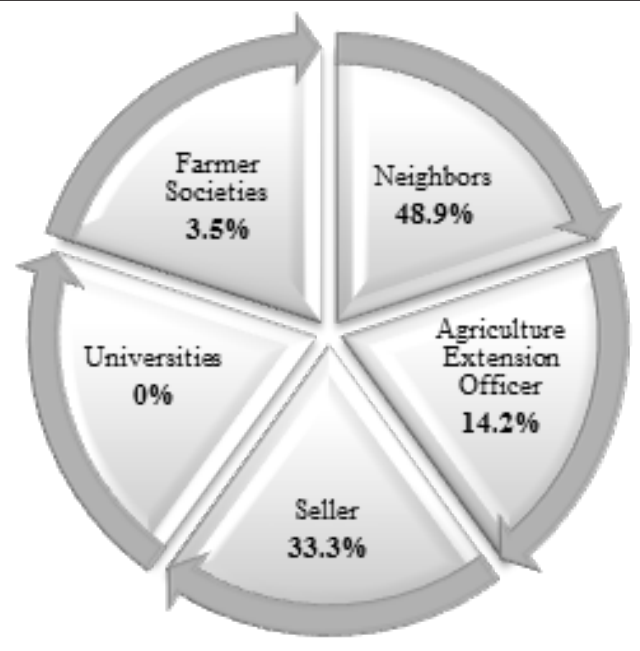

Figure 01: Ways of gathering information on Pesticides and other related

According to the Table 02, respondents have considered different factors when they buy a pesticide. The majority $(61.7 \%)$ of respondents has considered only about efficacy of pesticide and $38.3 \%$ have focused their attention on all including outer appearance, Ingredients and efficacy of pesticide. Some respondents are used to compare ingredients/ chemicals in pesticides and take a decision whether buy or not the particular pesticide.

Among all respondents $60.3 \%$ are aware about the companies who produce pesticides and $39.7 \%$ are lacking the knowledge on pesticide producers. View of some respondents was they just go to seller and take chemicals whatever the seller recommends without knowing brand name or company name.

The most interacted way of gathering information on pesticides and other related topics among respondents is from neighbors. It was $48.9 \%$ out of total and getting information from seller, agriculture extension officer and farmer societies resulted $33.3 \%, 14.2 \%$ and $3.5 \%$ respectively.

According to the results, $56 \%$ of farmers do not use any medium to gather information on pesticides/ chemicals and for other agriculture related things (Table 03). Instead of they acquire information from neighbors, seller, and agriculture extension officer or from farmer societies. But $36.9 \%$ of respondents gather information from television and 3.5\% and $1.4 \%$ of respondents gather information from radio and newspaper respectively. Out of total respondents $2.1 \%$ are getting information through various company activities such as company promotions, extension services, farmer society activities, etc.

Table 02: Factors considered when buying a pesticides

\begin{tabular}{lr}
\hline \multicolumn{1}{c}{ Factor } & Percentage \\
\hline Outer appearance & $0 \%$ \\
Ingredients & $0 \%$ \\
Efficacy & $61.7 \%$ \\
All & $38.3 \%$ \\
\hline
\end{tabular}


Table 03: Media used to gather information about Pesticide and other agricultural related things

\begin{tabular}{lrr}
\hline \multicolumn{1}{c}{ Medium } & Frequency & \multicolumn{2}{c}{ Percentage } \\
\hline Television (TV) & 52 & $36.9 \%$ \\
Radio & 5 & $3.5 \%$ \\
News Paper & 2 & $1.4 \%$ \\
Company Activities & 3 & $2.1 \%$ \\
Other/ No medium & 79 & $56.0 \%$ \\
\hline
\end{tabular}

Table 04 provides a descriptive tabulation of the explanatory variables used in this analysis.

Table 04: Descriptive Tabulation of Explanatory Variables

\begin{tabular}{|c|c|c|c|}
\hline Variables & Categories & $\mathrm{N}$ & Percentage \\
\hline Gender & $\begin{array}{l}\text { Male } \\
\text { Female }\end{array}$ & 141 & $100 \%$ \\
\hline Age & $\begin{array}{l}\text { Below } 20 \\
20-30 \\
31-40 \\
41-50 \\
\text { More than } 50\end{array}$ & $\begin{array}{r}0 \\
11 \\
20 \\
47 \\
63\end{array}$ & $\begin{array}{r}0.0 \% \\
7.8 \% \\
14.2 \% \\
33.3 \% \\
44.7 \%\end{array}$ \\
\hline Education & $\begin{array}{l}\text { No Schooling } \\
\text { Primary } \\
\text { Secondary } \\
\text { Diploma or Degree }\end{array}$ & $\begin{array}{r}5 \\
76 \\
59 \\
1\end{array}$ & $\begin{array}{r}3.5 \% \\
53.9 \% \\
41.8 \% \\
0.7 \%\end{array}$ \\
\hline Avg. Monthly income & $\begin{array}{l}\text { Rs. } 14,499 \text { or less } \\
\text { Rs. } 15,000 \text { - Rs. } 24,999 \\
\text { Rs. } 25,000 \text { - Rs. } 34,999 \\
\text { Rs. } 35,000 \text { - Rs. } 44,999 \\
\text { Rs. } 45,000 \text { or more }\end{array}$ & $\begin{array}{l}36 \\
24 \\
38 \\
12 \\
31\end{array}$ & $\begin{array}{r}25.5 \% \\
17.0 \% \\
27.0 \% \\
8.5 \% \\
22.0 \%\end{array}$ \\
\hline Pest intensity & $\begin{array}{l}\text { Very low } \\
\text { Low } \\
\text { Moderate } \\
\text { High } \\
\text { Very High }\end{array}$ & $\begin{array}{r}0 \\
11 \\
36 \\
54 \\
40\end{array}$ & $\begin{array}{r}0.0 \% \\
7.8 \% \\
25.5 \% \\
38.3 \% \\
28.4 \%\end{array}$ \\
\hline Mode of action of a pesticide & $\begin{array}{l}\text { Slow } \\
\text { Moderate } \\
\text { Fast }\end{array}$ & $\begin{array}{l}19 \\
39 \\
83\end{array}$ & $\begin{array}{l}13.5 \% \\
27.7 \% \\
58.9 \%\end{array}$ \\
\hline Spectrum of a pesticide & $\begin{array}{l}\text { Broad } \\
\text { Otherwise }\end{array}$ & $\begin{array}{r}125 \\
16\end{array}$ & $\begin{array}{l}88.7 \% \\
11.3 \%\end{array}$ \\
\hline Knowledge about quality \& Efficacious pesticides & $\begin{array}{l}\text { Good } \\
\text { Poor }\end{array}$ & $\begin{array}{r}116 \\
25\end{array}$ & $\begin{array}{l}82.3 \% \\
17.7 \%\end{array}$ \\
\hline Visiting of agricultural officer & $\begin{array}{l}\text { Yes } \\
\text { No }\end{array}$ & $\begin{array}{r}39 \\
102\end{array}$ & $\begin{array}{l}27.7 \% \\
72.3 \%\end{array}$ \\
\hline Acquiring of media for information & $\begin{array}{l}\text { Yes } \\
\text { No }\end{array}$ & $\begin{array}{l}62 \\
79\end{array}$ & $\begin{array}{l}44.0 \% \\
56.0 \%\end{array}$ \\
\hline Aware about the risk on health from pesticide use & $\begin{array}{l}\text { Fully } \\
\text { Partially } \\
\text { Less }\end{array}$ & $\begin{array}{r}107 \\
30 \\
4\end{array}$ & $\begin{array}{r}75.9 \% \\
21.3 \% \\
2.8 \%\end{array}$ \\
\hline Aware about the risk on environment from pesticide use & $\begin{array}{l}\text { Fully } \\
\text { Partially } \\
\text { Less }\end{array}$ & $\begin{array}{l}98 \\
32 \\
11\end{array}$ & $\begin{array}{r}69.5 \% \\
22.7 \% \\
7.8 \%\end{array}$ \\
\hline
\end{tabular}


All the respondents were male and 96.4\% had completed at least some college. About $55.3 \%$ of the participants were 50 years of age or below, while $69.5 \%$ of respondents had average monthly income of Rs. 34, 999 or less. Out of total, $92.2 \%$ of respondents had a moderate to very high pest intensity level. $58.9 \%$ and $88.7 \%$ of respondents preferred fast action and broad spectrum respectively. Out of total, $82.3 \%$ had a good knowledge about quality \& efficacious pesticides though the agriculture extension officer. Out of total, $75.9 \%$ and $69.5 \%$ of respondents were fully aware on the risk on health and environment from pesticides respectively.

\section{Outcome of the Chi-Square analysis}

According to the results of the chi-square analysis, six variables indicated a significant relationship with the response variable of farmers' perception and willingness to pay at 0.05 and 0.1 significant levels (Table 05).

\section{Outcome of the Binary Logistic Regression}

Table 06 shows the final results of the Binary Logistic regression using the most significant variables taken from the chi-square analysis. Four variables including age, average monthly income, pest intensity and action showed a significant impact to the response variable at 0.05 and 0.1 significant levels. Both average monthly income and action indicated a positive relationship while age and pest intensity indicated a negative relationship with the response variable. When, average income and action increase farmers' perception and willingness to pay will also increases. At the same time farmers' perception and willingness to pay tends to decrease when, age and pest intensity increase.

Table 05: Results of the Chi-Square analysis

\begin{tabular}{llll}
\hline \multicolumn{1}{c}{ Variable } & P-Value & \multicolumn{1}{c}{ Variable } & P-Value \\
\hline Age & $0.059^{* *}$ & Spectrum & $0.010^{*}$ \\
Education & 0.445 & Knowledge on Q/E & $0.060^{* *}$ \\
Avg. monthly income & $0.000^{*}$ & Extension officer & 0.573 \\
Pest Intensity & $0.064^{* *}$ & Media & 0.277 \\
Action & $0.020^{*}$ & Health risk & 0.849 \\
& & Environmental risk & 0.808 \\
\hline
\end{tabular}

P-Value $=$ Probability value of Pearson Chi-Square test

$*=$ Significance at 0.05 level $\quad * *=$ Significance at 0.1 level

Table 06: Results of the Binary Logistics Regression

\begin{tabular}{lrrll}
\hline \multicolumn{1}{c}{ Variable } & Coefficient $(\beta)$ & Standard Error & P-Value & Odds ratio \\
\hline Age & -1.02403 & 0.567467 & $0.071^{* *}$ & 0.36 \\
Avg. monthly income & 0.00029 & 0.000078 & $0.000^{*}$ & 1.00 \\
Pest intensity & -0.80951 & 0.417169 & $0.052 * *$ & 0.45 \\
Action & 1.78489 & 0.762035 & $0.019 *$ & 5.96 \\
Spectrum & 0.54205 & 0.924538 & 0.558 & 1.72 \\
Knowledge on Q/E & 0.09824 & 0.819235 & 0.905 & 1.10 \\
* Significance at 0.05 level & \multicolumn{3}{c}{$* *=$ Significance at 0.1 level }
\end{tabular}




\section{CONCLUSIONS}

All the respondents of the study were male and the majority of them are used to handle chemicals without engaging in traditional methods of controlling pests because of high time consumption, need of large quantities and the application problems of traditional methods. But still farmers believe that the traditional methods are long lasting and successful than chemical solutions. If farmers are well equipped from materials, money and also from knowledge about traditional methods and its' advantages, still there is a possibility of making their mind set towards traditional pest control methods.

When concern about brand loyalty or product loyalty of farmers on pesticides, a considerable portion of farmers do not believe that a particular product will perform well for long period as same as the first application. As a result of they always try to shift from one product to another. When farmers' buy a pesticide most of them concern only about efficacy of that product and do not consider on other components like outer appearance, Ingredients, etc.
Most of the farmers are interested of getting ideas from neighbor farmers because; they believe that farmers have the experience of working with field than agriculture officers, sellers and other people. But some part of the farmers tends to get opinions from the pesticide sellers also.

Use of media among farmers is considerably poor. More than half are not getting the use of media. Television is the most effective mass media followed by radio, company activities and news paper respectively.

The results revealed that four variables namely; age, average monthly income, pest intensity and action have a significant relationship with farmers' perception and willingness to pay for pesticides concerning quality and efficacy. Average monthly income and action have a positive impact on perception and willingness to pay while age and pest intensity have a negative impact. Therefore those factors are the variables which can change farmers' perception and willingness to pay for pesticides concerning quality and efficacy towards positive or negative.

\section{REFERENCES}

Adetonah, S., Coulibaly, O., Nouhoheflin, T., Kooyman, C. and Kpindou, D. (2007). Farmers' Perceptions and Willingness to Pay for Metarhizium-based Biopesticide to Control Cotton Bollworms in Benin (West Africa). AAAE Conference Proceedings, 315-319.

Govindasamy, R., Italia, J. and Adelaja, A. (2001). Predicting Willingness-to-Pay a Premium for Integrated Pest Management Produce: A Logistic Approach. Agricultural and Resource Economics Review, 30 (2), 151-159.

Action Group on Erosion, Technology and Concentration (2008) "Who Owns Nature? Corporate Power and the Final Frontier in the Commodification of Life". 